\title{
Energy Loss in Solar Photovoltaic Systems Under Snowy Conditions
}

\author{
Anis Haque, Namrata Sheth \\ Department of Electrical and Computer Engineering, University of Calgary, Calgary, Canada \\ Email address: \\ sahaque@ucalgary.ca (A. Haque), namrata.sheth@ucalgary.ca (N. Sheth) \\ To cite this article: \\ Anis Haque, Namrata Sheth. Energy Loss in Solar Photovoltaic Systems Under Snowy Conditions. Journal of Electrical and Electronic \\ Engineering. Vol. 5, No. 6, 2017, pp. 209-214. doi: 10.11648/j.jeee.20170506.11
}

Received: October 20, 2017; Accepted: November 1, 2017; Published: December 12, 2017

\begin{abstract}
The objective of this study is to quantify the energy loss due to snow on solar photovoltaic systems. Solar photovoltaic systems in cold temperatures have an advantage over warmer regions due to improved efficiencies. However, colder regions generally receive a significant amount of snow, which may hinder the energy output of the photovoltaic systems. For this experimental research, a solar photovoltaic system was set up in Calgary, Canada to analyze and quantify the energy losses due to snow. This research demonstrates a 9\% loss in energy yield per year due to snow accumulation in absence of bypass diodes.
\end{abstract}

Keywords: Effect of Snow, Efficiency, Energy Loss, Performance, Renewable Energy, Snow Accumulation and Melting, Solar Photovoltaic (PV) Systems, Temperature Effect

\section{Introduction}

Solar photovoltaic (PV) systems are well-adept for cold climates, as it is a known fact that PV systems have better efficiencies in colder temperatures (Rahim, Rahim, J. Selvaraj, \& Tyagi, 2013). However, there is a significant amount of snow precipitation in cold climates, which may hinder the electricity generation ability of PV systems due to factors like snow accumulation and shading.

The term 'cold climate' can have many connotations, but for the purpose of this paper, it is defined as a climate which generally has freezing temperatures, snow, dark winters, and long summer days for more than a few months of the year. These factors are important to consider when designing a PV system. Calgary, being in Southern Alberta, is situated in one of the higher irradiance regions of Canada (Natural Resources Canada, 2015). Thus, it has a natural advantage to harness this abundant solar resource. However, it normally receives a significant amount of snow per year, approximately $150 \mathrm{~cm}$ for an average of 54.2 days. [3-4]. Hence, Calgary was well suited for this experiment, as the purpose of this research was to explore the effect of snow precipitation, accumulation, and melting on solar PV systems. Understanding and improving the performance of PV systems is important, since investment into these systems can address two of the most significant problems that exist in the world today - growing energy demand and increasing greenhouse gas emissions.

\section{Background}

Power output of a solar PV system depends on various factors such as irradiance, cell temperature, and shading, among others. Current produced in the panel is determined by the irradiance incident on it, such that lower the irradiance, lower the current produced. Thus, as irradiance changes throughout the day, so does the power output (Islam, Rahman, $\&$ Mominuzzaman, 2014). Although voltage induced in the panel is not affected by the irradiance directly, the cell temperature and the ambient temperature significantly affect the voltage across the panel. Thus, the power generated by the panel is also affected with change in temperature (The German Energy Society, 2008).

Irradiance, which is incident solar energy on a panel depends on several factors such as the angle of elevation of the panel, orientation of the panel, shading due to the surroundings, and climatic factors, like dust, snow, and precipitation. Shade can obstruct solar radiation to fully reach the panel, thus disabling the particular cells from producing electricity, which can subsequently start to behave like a load and consume the current. In some instances, depending upon 
the position of the shaded cells, a breakdown voltage could be achieved, leading to reverse current flow. In such scenarios, this can result in the development of a hotspot, where significant damage could occur to the panel if the heat is high. To minimize such damages, bypass diodes are inserted in the panel so that it does not act as a load. Hence, the excess reverse current is diverted and passed through these bypass diodes instead of the shaded cells (Sasmita \& Samantaray, 2016).

Snow is interconnected to all three factors mentioned above that affect the electric performance of a solar panel temperature, irradiance, and shading. As snow generally precipitates at low temperatures, the efficiency is influenced positively due to the temperature dependence factor. However, the accumulated snow also acts as a shade on the panel, which obstructs the irradiance reaching the panel, thus impacting the efficiency negatively. Hence, it is a complex phenomenon that warrants thorough research and understanding.

There have been a few studies on the effects of snow on PV systems in different places, such as USA, Germany, Ontario (Canada), showing that power generation losses in PV systems due to snow are dependent on the snowmelt behavior and the degree of snow accumulation on the panel [8-9]. Snow accumulation is dependent on the inclination of the modules, ambient temperature, wind speeds, and surface properties (Andrews, Pollard, \& Pearce, 2013). A study in Michigan showed that the electricity generation losses due to snow can be as high as $24-34 \%$ (Heidari, Gwamuri, Townsend, \& Pearce, 2015) for modules with low tilt angle; likewise, losses can range to as low as $0.3-2.7 \%$ in Germany for a highly-tilted roof mount system (Andrews, Pollard, \& Pearce, 2013). However, it is important to note that the optimum mounting angle for a particular region in sunny conditions would not necessarily be the same as the optimum mounting angle for snow melting. Thus, the energy losses due to snow would be different for various regions and conditions.

\section{Methodology}

A solar panel of $140 \mathrm{~W}$ was set up at the University of Calgary (latitude $51^{\circ} 4^{\prime} 47.8128^{\prime \prime} \mathrm{N}$ and longitude $114^{\circ} 7^{\prime}$ 31.9224" W) for this experiment during the months of January to April. Current and voltage data from the panel were collected every ten minutes, along with the photographs of the panel and its surroundings. The photographs were clicked with a SONY handy camera for the experiment's period to observe snow accumulation and melting behaviour on the panel.

\subsection{Experimental Setup, Data Collection, and Filtration}

A KYOCERA KDSX140 UPU solar panel was used, with $\mathrm{V}_{\max }=17.7 \mathrm{~V}, \mathrm{I}_{\max }=7.91 \mathrm{~A}, \mathrm{~V}_{\mathrm{OC}}=22.1 \mathrm{~V}$, and $\mathrm{I}_{\mathrm{SC}}=8.68 \mathrm{~A}$ (KYOCERA KD 135 P, SX Series). For this study, bypass diodes were removed from the panel to determine the actual effect of snow accumulation on the electric performance and energy yield of the panel. The load used for this setup was 10 $\Omega$, which was obtained using a rheostat. LabVIEW was used to design the software for the data acquisition system to collect data in spreadsheets.

As shown in the circuit diagram of the system setup in figure 1, the load was connected in parallel with the panel. Voltage $(V)$ was measured across the load using a voltmeter in volts, and the current $(I)$ flowing into the load was measured using an ammeter in amperes.

The power across the load was calculated by multiplying the voltage and current, which was the practical power $\left(P_{P R}\right)$ across the load at a given time.

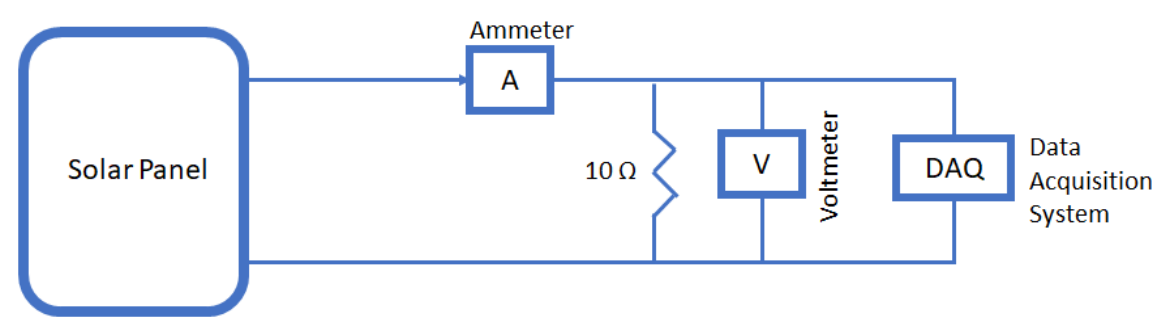

Figure 1. Circuit Diagram of the System Setup.

The local irradiance and weather information for the analysis were collected from the University's weather station. Weather data included irradiance in $\mathrm{W} / \mathrm{m}^{2}$, ambient temperature in ${ }^{\circ} \mathrm{C}$, and precipitation in $\mathrm{mm}$. A pyranometer was used to find the local horizontal irradiance at the University. According to its datasheet, there was a system accuracy of $\pm 1.6 \%$ in the readings [11-12], which was taken into consideration during data analysis.

\subsection{Performance Ratio}

As the objective of this study was to find the sole impact of snow on the module, the effects from all other factors were discarded. To separate the power loss due to factors other than snow, a quantity was introduced, called the performance ratio. The 'Performance Ratio' or ' $K$ factor' was found by dividing $\mathrm{P}_{\mathrm{PR}}$ to the calculated theoretical power $\left(P_{T H}\right)$ at any instant as given in (1).

$$
\text { Performance Ratio or } K=\frac{P_{P R}}{P_{T H}}
$$

For this research, daytime was defined as the time between average sunrise and sunset for a given month. The first step was to filter and sort daytime values of $V$ and $I$ for the experiment's period and calculate $P_{P R}$. Next, graphs for daytime values of $P_{P R}$ versus time were plotted to observe the trends. Then, the panel's photographs were observed to 
distinguish snowy days from non-snowy days. For this study, a 'snowy day' was defined as any given day in which at least $10 \%$ of the panel was covered with snow for a more than half of the daytime. Alternately, a 'non-snowy day' was defined as any clear day with no snow accumulation on the panel. Subsequently, all snowy days for each month were journaled, along with information about the durations of snow accumulation on the panel.

The aim was to find the percentage performance loss of the panel due to snow by comparing the performance ratio on snowy days to non-snowy days. A total of 17 snowy days were found in the measured data that satisfied the definition of 'snowy day' for this analysis. Then, the average performance ratio $\left(K_{S}\right)$ for tabled snowy days was calculated using (2). For fair comparison of performance ratios, data was analyzed for approximately the same number of non-snowy days. Using the same equation, average performance ratio for non-snowy days $\left(K_{N S}\right)$ was then calculated.

In equation (1), calculated theoretical power $\left(P_{T H}\right)$ was found using (2) (The German Energy Society, 2008). To improve the accuracy of the analysis, temperature effect on efficiency of the panel was taken into account due of low temperatures in Calgary. In equation (2), $\eta_{\text {cell }}$ is the cell or panel efficiency at a given cell temperature and $S_{\text {mod }}$ is the actual irradiance reaching the panel. Area of the panel was $0.8649 \mathrm{~m}^{2}$, obtained from the data sheet for the panel.

$$
P_{T H}=\eta_{\text {cell }} \times \text { Area of the panel x } S_{\text {mod }}
$$

As efficiency is dependent on the temperature of the module, it was necessary to calculate $\eta_{\text {cell }}$, and is given by (3), which was obtained from (Dubey, Sarvaiya, \& Seshadri, 2012). In equation (3), $\beta_{R E F}$ is the temperature coefficient of the panel and $\mathrm{T}_{\text {ref }}$ is the reference temperature at Standard Test Conditions (STC) temperature of $25^{\circ} \mathrm{C}$ and $1000 \mathrm{~W} / \mathrm{m}^{2} . \eta_{S T C}$ is the efficiency of the panel at STC, as calculated in (4) $(\mathrm{Li}$, Duell, \& Schuhmacher, 2010). $T_{\text {cell }}$ is the temperature of the module at a given ambient temperature, which is found by (5).

$$
\begin{aligned}
\eta_{\text {cell }} & =\eta_{\text {STC }}\left[1-\beta_{\text {REF }}\left(T_{\text {cell }}-T_{\text {ref }}\right)\right] \\
\mathrm{D}_{\mathrm{STC}} & =\frac{I_{\max } \times V_{\max }}{\operatorname{Area}(A) * \operatorname{Irradiance}(E)}=0.16
\end{aligned}
$$

$T_{A m}$ is the ambient temperature, which was acquired from the weather station data at any given instant. $N_{O C T}$ is the nominal operating cell temperature which was $45^{\circ} \mathrm{C}$ for this experiment (KYOCERA KD 135 P, SX Series). $S_{\text {mod }}$ is the irradiance reaching the module, as given by (6), which is also used in (2).

$$
T_{\text {cell }}=T_{A m}+\left[\frac{\left(N_{o c t}-20\right)}{8} * S_{m o d}\right]
$$

$S_{\text {hori }}$ is the irradiance reaching the pyranometer lying horizontally on the surface of earth, which measures the incoming irradiance. $S_{\text {hori }}$ was known from the data collected by the university's weather station. It should be noted that the irradiance reaching the panel $\left(S_{m o d}\right)$ was different from the irradiance reaching the pyranometer $\left(S_{\text {hor }}\right)$, since both the pyranometer and the panel were mounted at different tilt angles. Thus, $S_{\text {mod }}$ which is the irradiance (in $\mathrm{W} / \mathrm{m}^{2}$ ) reaching the panel, calculated using (6) [15-17].

$$
S_{\text {mod }}=\frac{S_{\text {hori }} * \sin (\alpha+\beta)}{\sin (\alpha)}
$$

$\mathrm{D}$ is the day of the year which is used in (5) to calculate $\delta$, the declination angle found in reference (Baklouti, Driss, \& Abid, 2012). For this experiment, the panel was fixed and mounted at the tilt angle of $\beta=44^{\circ}$ which is the optimum tilt angle for Calgary for best average irradiance reaching the panel throughout the year. Additionally, $\alpha$ is the elevation angle and is given by (7) and $\varphi$ is Calgary's latitude $=51^{\circ}$.

$$
\begin{gathered}
\alpha=90-\varphi+\delta ; \\
\delta=23.45^{\circ} * \sin \left(\frac{360 *(284+D)}{365}\right) .
\end{gathered}
$$

It is necessary to note that the current measured in this system was the current through the load. Thus, the practical power $P_{P R}$, is the power from the load. But the theoretical power $P_{T H}$ calculated from (1) is the theoretical power from the solar cell. Thus, modifications are made such that the equations to calculate performance ratio can be used fairly. Hence, the I-V curve for this panel was retrieved from PVsyst software according to which, for a load value of $10 \Omega$, maximum theoretical power for the resistor is calculated to be 47 W (PVSyst Software, 2016). Therefore, to have a valid comparison of powers in (1), whenever $P_{T H}$ value calculated from (1) goes above $47 \mathrm{~W}$, the denominator in the $K$ factor's equation is taken as $47 \mathrm{~W}$.

Furthermore, to increase the accuracy of this analysis, the performance ratio of snowy days was calculated only after the radiometers at the weather station are cleaned and brushed off in the mornings, and errors are minimized. Subsequently, if the radiometer of the weather station was not brushed on the same day, then $K$ values were taken into account only after an hour of the sunrise and before an hour of sunset, so accuracy in calculations was maintained. Moreover, the weather data regarding snow precipitation was also verified from Environment Canada Resources (Environment Canada, 2003).

\subsection{Energy Yield under Snowy Conditions}

The performance loss of the panel for snowy days gives an idea of the impact of snow on PV systems. Taking a step further, energy loss due to snow is determined. To calculate the energy loss on tabled snowy days, first, actual energy yield $\left(E_{P R}\right)$ is found by summing the area under the $P_{P R}$ versus time curve, using the trapezoid area method in MS Excel.

Then, the hypothetical power under supposed no snow scenario $\left(\right.$ Power $\left._{H N S}\right)$ is calculated using (9) by factoring in the performance ratio of the panel in hypothetical no snow conditions. Then, the hypothetical energy yield for snowy days is found using the same trapezoidal method in Excel.

$$
\text { Power }_{\mathrm{HNS}}=\frac{0.78 \times \text { Power }_{P R}}{K_{S}}
$$


The actual energy yield $\left(E_{P R}\right)$ and hypothetical energy yield $\left(E_{N H S}\right)$ are then summed up for the selected snowy days. Next, the difference is compared to find the energy loss for particular snowy days. Lastly, this loss is extrapolated to an average energy loss for an average year. This energy loss per year is the number that could be useful in system designing and in economic analysis for a specific PV system. While interpreting the energy loss per year, it is necessary to acknowledge the fact that there are no bypass diodes in place, so that the actual loss due to snow is known.

\section{Experiment Findings and Interpretation}

\subsection{Performance Loss and Energy Loss due to Snow}

Theoretically, the performance ratio for a non-snowy day is $100 \%$; however, due to factors other than snow, such as external shadow on the panel, other climatic and technical conditions, there are various system losses. Therefore, the actual $K_{N S}$ is lower than $100 \%$ (The German Energy Society, 2008). For this panel, the average performance ratio on non-snowy days was found to be $K_{N S}=0.78$, which signifies that on any non-snowy day, the panel has an average performance of $78 \%$ of its total efficiency.

The average performance ratio for snowy days, $K_{S}$, was calculated to be 0.33 , which represents that the average performance of the panel on a snowy day is 33\% of it's efficiency. This demonstrates that, on average, the performance of the panel (in the absence of bypass diodes) decreased from $78 \%$ to $33 \%$ on snowy days of Winter 2014 in Calgary. The performance of the module on selected snowy and non-snowy days is shown in figure 2. Therefore, the loss in performance of the panel due to only snow was $57 \%$, which was calculated by comparing $K_{S}$ to $K_{N S}$.

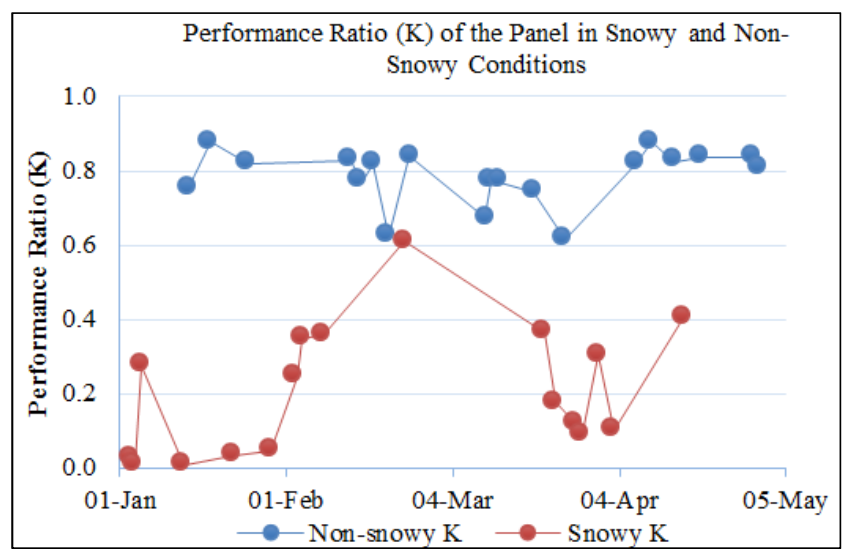

Figure 2. Performance Ratio Comparison for Snowy and Non-Snowy Days.

Subsequently, the actual and hypothetical energy yields were then summed up for all the selected snowy days and the difference was then compared to find the loss in energy yield. The loss was calculated to $61 \%$, which implies that there was a $61 \%$ loss in the actual energy delivered to the load for the selected snowy days. This energy loss can be attributed directly to snow, since other losses were already eliminated. However, there may be other unknown factors that can cause losses to the system; however, it can be considered as minor, due to which, a small error was estimated in the analysis. Given that Calgary experiences 54.2 snowy days in an average year (Current Results - Weatehr and Science Facts, 2016), energy loss was then extrapolated from the selected snowy days to the entire year. The final result demonstrated that in the absence of bypass diodes, energy loss in Calgary per year purely due to snow was approximately 9\%. The comparison between hypothetical and actual energy yield on selected snowy days is show in figure 3 , and the difference between the actual and hypothetical yields represents the energy loss due to snow.

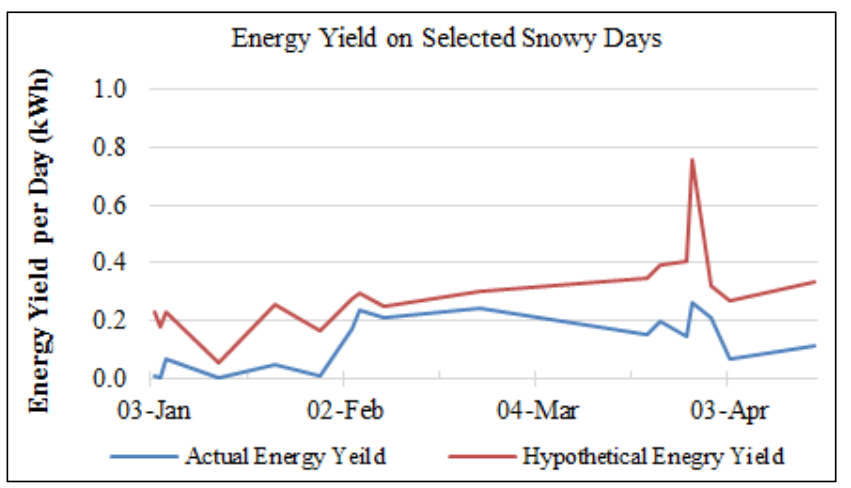

Figure 3. Actual and theoretical energy yield comparison on selected snowy days.

\subsection{Snow Accumulation and Melting Behavior}

An interesting phenomenon was observed during the data analysis in the month of February. Due to relatively high irradiation, when the accumulated snow was melted off the panel, there was a sudden increase in the power output. This phenomenon could have been caused as a result of low panel temperature (due to snow accumulation on the panel's surface), which likely increased the efficiency of the panel temporarily. Furthermore, the resistance of the load decreased due to low temperature, thus leading to increase in current flow and hence, the increase in power. An example of this observation was noted on $4^{\text {th }}$ February, when the snow melted off completely in 20 minutes and an abrupt increase in power output was observed immediately after the snow melted completely as shown in figure 4 and figure 5 .

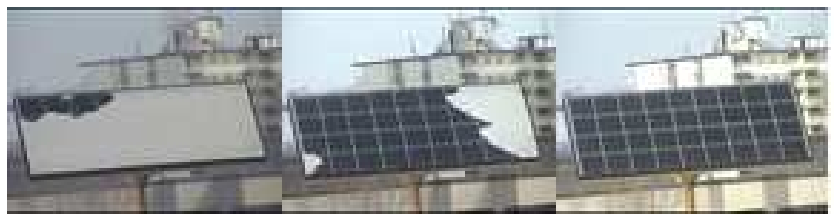

Figure 4. Complete snow melting on the panel within 20 on $4^{\text {th }}$ February from 11:55 AM to 12:05PM.

Another observation in the analysis was that the snow melting behaviour on the panel seemed to be dependent on a number of factors. The factors observed are: 
1. Ambient temperature

2. Module temperature

3. Snow thickness on the panel

4. Type of snow material

5. Irradiance

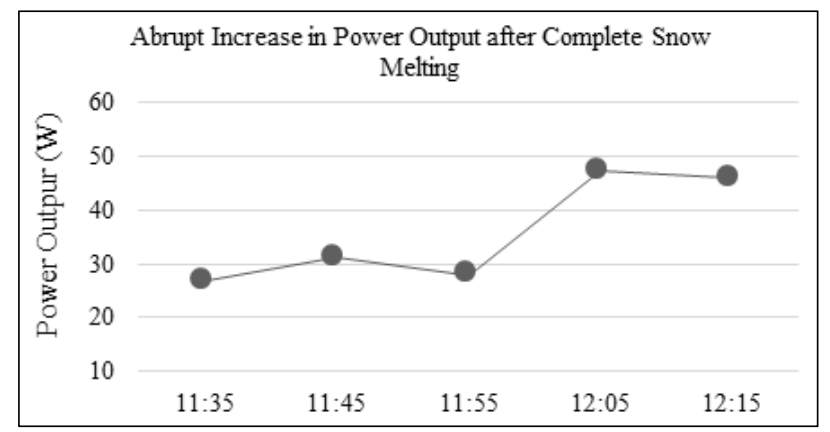

Figure 5. Abrupt increase in power output after complete snow melting on $4^{\text {th }}$ February, corresponding to figure 4.

Two different scenarios are shown in figure 6. In Case 1, the snow accumulation had light to medium thickness and could be described as patchy. It melted in an uneven way and complete melting took 30 minutes. On the other hand, in Case 2 , snow accumulation was very thick and non-patchy. Snow melt occurred in slabs and took 45 minutes for complete melt.
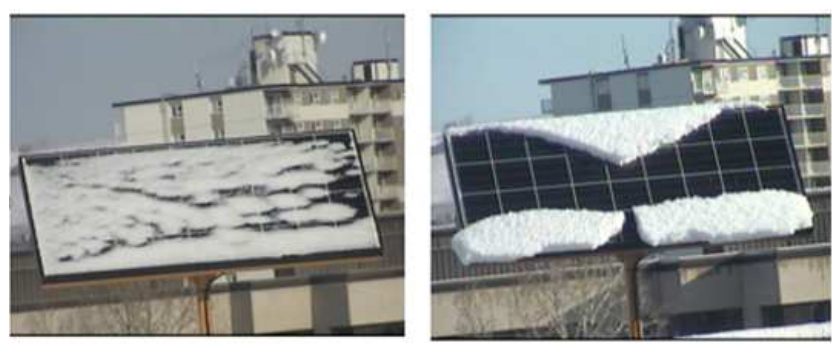

Figure 6. Snow Melting Case 1 (Patchy) and Case 2 (Slab).

Thus, snow melt on the panel is a multipart phenomenon due of a myriad of factors, such as ambient temperature, irradiance, and module temperature, which are interconnected with each other in complex relationships.

\section{Conclusion}

The result of this analysis demonstrated that there was an approximately $9 \%$ loss in energy yield per year in Calgary, without bypass diodes in the solar PV system. An error estimation of $\pm 5 \%$ was included, due to few faults in weather station data, power measurements, and the modifications used for calculations. It is important to acknowledge the fact that this energy loss per year is without the use of bypass diodes.

According to a study in Calgary, representing a sample population for snowy regions, public perception about PV performance in cold climates is such that more than $85 \%$ of the people surveyed (approximately 300 in total) were not aware that cold temperatures are actually beneficial for PV performance (Haque, 2016). Therefore, this research paper could be utilized to encourage the general public in snowy regions to invest in PV systems, as the need for renewable energy is increasing day by day.

\section{References}

[1] N. A. Rahim, N. A. A. Rahim, J. Selvaraj and V. V. Tyagi, "Outdoor performance of solar PV/T air system," in IEEE Conference on Clean Energy and Technology (CEAT), Lankgkawi, Malaysia, 2013.

[2] Natural Resources Canada, "Photovoltaic potential and solar resource maps of Canada," Canada, 2015.

[3] Current Results - Weatehr and Science Facts, "Calgary Snowfall Totals \& Accumulation Averages," 2016.

[4] Calgary Weatherstats, "Calgary Historical Snowfall," 2016.

[5] M. N. Islam, M. Z. Rahman and S. M. Mominuzzaman, "The effect of irradiation on different parameters of monocrystalline photovoltaic solar cell," in 3rd International IEEE Conference on the Developments in Renewable Energy Technology (ICDRET), Dhaka, Bangladesh, 2014.

[6] The German Energy Society, "PV Classification," in Planning and Instaling PV Systems, Germany, Earthscan, 2008, p. 357.

[7] S. Sasmita and P. Samantaray, "Performance of solar photovoltaic module under partial shading conditions," in 10th International IEEE Conference on Intelligent Systems and Control (ISCO), Coimbatore, India, 2016.

[8] R. Andrews, A. Pollard and J. Pearce, "The Effect of Snowfall on Photovoltaic Performance," Solar Energy, vol. 92, pp. 84-97, June 2013.

[9] N. Heidari, J. Gwamuri, T. Townsend and J. M. Pearce, "Impact of snow and ground interference on photovoltaic electric system performance," IEEE Journal of Photovoltaics, vol. 5, no. 6 , pp. 1680 - 1685, 2015.

[10] KYOCERA KD 135 P, SX Series, "Electrical Specifications," KYOCERA Solar Inc.

[11] Campbell Scientific Inc, "Precision Spectral Pyranometer Instructor manual," 1992.

[12] University of Calgary, "University of Calgary Weather Research Station Logger Data Notes," Calgary, 2016.

[13] S. Dubey, J. Sarvaiya and B. Seshadri, "Temperature Dependent Photovoltaic (PV) Efficiency and Its Effect on PV Production in the World A Review," Energy Procedia, vol. 33, pp. 311-321, 2012.

[14] B. Li, M. Duell and T. Schuhmacher, "Prediction of PV module nominal operating cell temperature using electromagnetic wave modeling," in IEEE Photovoltaic Specialists Conference (PVSC), 2, Honolulu, HI, USA, 2010.

[15] C. Honsberg and S. Bowden, "Solar Radiation on a Tilted Surface," 2014. [Online]. Available: $\mathrm{http} / /$ www.pveducation.org/pvcdrom/properties-of-sunlight/s olar-radiation-on-tilted-surface.

[16] A. Ahmed and M. Reha, "Optimizing Bangladeshi solar home system efficiency using two-position mount," in IEEE COnference on Developments in Renewable Energy Technology (ICDRET), Dhaka, Bangladesh, 2014. 
[17] R. Bird and C. Riordan, "Simple solar spectral model for direct and diffuse irradiance on horizontal and tilted planes at the Earth's surface for cloudless atmospheres," Journal of Climate and Applied Meteorology, vol. 25, pp. 87-97, 1986.

[18] I. Baklouti, Z. Driss and M. S. Abid, "Estimation of solar radiation on horizontal and inclined surfaces in Sfax, Tunisia," in IEEE First International Conference on Renewable Energies and Vehicular Technology (REVET), Hammamet, Tunisia, 2012.
[19] PVSyst Software, "PVSyst Software," 2016.

[20] Environment Canada, "Annual solar Radiation of Alberta," Chetner and the Agroclimatic Atlas Working Group, 2003.

[21] A. Haque, "Comparison of 1 MW Grid-Connected PV System and a StandAlone System to Determine Canada's Potential," IOSR Journal of Electrical and Electronics Engineering, vol. 11, no. 6, pp. 91-99, 2016. 